\title{
LA VIOLENCIA Y LO INFAUSTO. VIVENCIAS DE LOS ROTOS CHILENOS EN LAS FAENAS CARRILANAS EN LA LÍNEA AREQUIPA-PUNO, 1871-1872, A LA LUZ DE DOS DOCUMENTOS INÉDITOS. CON INTRODUCCIÓN Y NOTAS
}

[Violence and the Infamous. Experiences of Chilean rotos (Working Class People in the XIX Century) in the Railroad Works in Arequipa-Puno Railway, 18711872, In light of two Unpublished Documents. With Introduction and notes]

\author{
Gilberto Juan HarRis Bucher* \\ Universidad de Playa Ancha, Valparaíso, Chile
}

\begin{abstract}
RESUMEN
Se reproducen, precedidos de introducción y notas, dos documentos inéditos depositados en el Fondo Ministerio de Relaciones Exteriores del Archivo Nacional que muestran a las claras el clima de violencia, excesos y hechos infaustos que debieron capear miles de carrilanos chilenos contratados para trabajar en la línea de Arequipa-Puno en los años de 1871 y 1872, todo en el marco de los 25.000 a 30.000 mapochinos reclutados para una gigantesca obra ingenieril ferroviaria dirigida por Enrique Meiggs, el cual auspició y fomentó junto con ingenieros y mayordomos como Campbell, Mayo, Tomas, Wiman, Retamal, Anrique todo tipo de excesos y tropelías contra los nuestros, contando además con la complicidad de las fuerzas
\end{abstract}

\begin{abstract}
Two unpublished documents under the custody of the Archive of the Ministry of Foreign Affairs have been reproduced including an introduction and notes. These clearly evidence the violence, excesses and infamous events that thousands of Chilean railroad workers suffered when working in the railroad of the Arequipa-Puno railway between 1870 and 1871 . This event corresponds to the 25.000 to 30.000 Mapochinos that were hired to build an enormous railway engineering work directed by Enrique Meiggs who, along with other engineers and administrators such as Campbell, Mayo, Tomas, Wiman, Retamal, Anrique, allowed all sorts of excesses and outraging situations against fellow Chileans, also with the complicity of
\end{abstract}

RECIBIDO el 22 de agosto de 2017 y ACEPTADO el 14 de junio de 2018

* Gilberto Juan Harris es Profesor Titular del Departamento Disciplinario de Historia, de la Universidad de Playa Ancha (Valparaíso, Chile). gilberto.harris@upla.cl. 
de orden y los jueces peruanos para denegar todo tipo de justicia.

\section{Palabras ClaVe}

Faenas carrilanas - derecho del trabajo - abusos laborales - Arequipa - Puno. the forces of law and order and the Peruvian judges to deny any type of unfair treatment.

\section{KEYWORDS}

Railroad works - Labor law - labor abuses - Arequipa - Puno.

\section{INTRODUCCIÓN}

La historiografía tradicional ha tratado con superlativos adjetivos la dirección de los trabajos del norteamericano Enrique Meiggs en la construcción del Ferrocarril entre Valparaíso y Santiago, enfatizando en la buena paga, trato y comida con nuestros r o tos y que obtuvo una suculenta recompensa en metálico por haber finalizado, con antelación, el término del contrato el trazado de la mentada vía $^{1}$. En verdad, exagerando, poco ha faltado para que haya sido retratado como una persona de incombustible bonhomía y empatía con nuestros compatriotas carrilanos.

Con todo, la cuasi q u i m é r i c a aventura en el Perú, ya veremos por qué aunque sea con solo dos documentos pero muy circunstanciados, no pasó desapercibida para nuestras autoridades centrales noticiadas de que eran conducidos nuestros peones como r e b a ñ o por los agentes del contratista Meiggs, y después de tanta noticia infausta el canciller Ibáñez ordenaba el arresto de cualquier individuo bajo sospecha de reclutar peones hacia el Perú .

Ahora bien, los dos documentos inéditos sobre los que ya nos explayaremos y que son la parte central de este estudio -algo garabateados y en algunos pasajes ilegibles puesto que fueron escritos en papel muy común y con no buena pluma por trabajadores de la mencionada vía- revelan de manera irrecusable que en el marco de la salida de los 25.000 a 30.000 mapochinos que llevó al Perú entre 1869

${ }^{1}$ Véase, para todo, Marín, Santiago, Estudio de los Ferrocarriles Chilenos (Santiago, 1901), passim. Particularizando, Meiggs llegó a señalar que los rotos chilenos "están dispuestos a trabajar conmigo por un plato de porotos y un poco de justicia”. Vid. Fernández ConQue, Manuel, Formación del proletariado en el norte chileno, en Revista Camanchaca, 4 (Iquique, 1987), p. 16. Inclusive en Wikipedia, fuente poco confiable, a propósito de Enrique Meiggs, se indica que en el tramo Mollendo-Arequipa trabajaron 2.000 chilenos "devotos a él" (sic). Gabriel Salazar, en Los patrones colocaban a los inquilinos desnudos y los azotaban con varillas en la espalda, en The Clinic, 9/249 (Santiago, 2008) plantea que “35.000 (sic) rotos se fueron al Perú siguiendo a Enrique Meiggs [...] [él] cumplió su palabra y pagó lo prometido. No como acá”, afirmación que es un error. Nosotros también nos equivocamos al señalar en otro escrito que Enrique Meiggs levó un contingente de 5.000 mapochinos para trabajos carrilanos en Costa Rica, grueso error puesto que fue Minor Keith casada con una hermana del Meiggs de marras. Y eso nos ha ocurrido por confiar en historiadores no documentados, y por lo mismo repetimos por inercia una errata importante. Todo debe ser blindado.

2 A. Prieto y Cruz al Ministro del Interior (Valparaíso, 17 de marzo de 1870), en Archivo Nacional, Fondo Ministerio del Interior, vol. 602; y, Circular de Ibáñez a los Intendentes (Santiago, 22 de marzo de 1872), en Archivo Nacional. Fondo Intendencia de Valparaiso, vol. 264. 
y $1872^{3}$, el propio Meiggs auspició, con la ayuda de un ejército de subalternos, mayordomos y fuerzas de orden del país del Rimac, un trato altamente violento, vejatorio e inhumano contra los nuestros que incluyó no solo los grilletes, el cepo y el látigo, sino que también tiros de revólver, encierros prolongados, negativa de administrar alimentos, no pago de jornales y también obligándolos a seguir trabajando en las tareas carrilanas a pesar de haber fenecidas las contratas, incluyendo por cierto los castigos, arrestos y denegación de justicia para nuestros paisanos de parte de los jueces peruanos.

El barbarismo antichileno, que queda patente en los dos documentos que anexamos, se suma a una larga historia marcada por lo infausto respecto de quienes abandonaban nuestros lindes por mejores trabajos y buena paga, labores auspiciadas muchas veces para los que no existía ni Dios ni Ley, cuestiones que en casi todas las latitudes se replicaron lamentablemente como hemos señalado en un reciente estudio apoyados en una sobretasa de información documental ${ }^{4}$.

También consignemos que Meiggs, "el Pizarro yankee" -término acuñado por Watt Stewart- dio patentes muestras de indolencia y cinismo respecto de los chilenos, a propósito de cierto discurso pronunciado en el Perú en 1872: "No era justo [señaló Meiggs] hablar de miseria cuando no existe ni podía existir; tampoco era necesario ni justo pintar los valles del Perú como un inmenso camposanto de los chilenos. Aquí se muere como en cualquiera otra parte del globo"5. La última parte del discurso fue corroborada, con exageraciones por cierto, en 1884 por el articulista L.L. Venegas al señalar que "casi la mayor parte de las líneas férreas que cruzan la costa del Perú, sino todas los cadáveres chilenos las más de las veces [quedaron] insepultos al lado de los terraplenes, hasta llegar a contarse un cadáver por cada durmiente tendido [...]"6. Pero es del caso no olvidar aquí que

\footnotetext{
${ }^{3}$ Véase STeWART, Watt, El trabajador chileno y los ferrocarriles del Perú, en Revista Chilena de Historia y Geografia, 93 (1938), p. 55.

${ }^{4}$ Harris BuCher, Gilberto, Emigrantes e inmigrantes en Chile, 1810-1915. Todo revisitado. Todo recargado (Valparaíso, 2012), I parte. En verdad, lamentablemente un sino trágico ha acompañado por siempre a nuestros rotos en sus periplos por tierras extrañas e inclusive cuando fueron repatriados a la nación. Un triste botón: a pesar de haber sido dictada una ley de recompensas en favor de los soldados de la Guerra del Pacífico, aquella no era cumplida "y dictada la ley los pobres rotos alzaron las manos al cielo y exclamaron con las lágrimas en los ojos gracias oh patria, gracias. Acabas de probarnos que es un sangriento sarcasmo lo del Pago de Chile, pero pasó un mes, pasaron dos, pasaron tres, cuatro, cinco y seis [...] y las recompensas no llegaron. Nada, nada y nada”. El Padre Cobos. Santiago, 30 de mayo de 1882, en Salinas, Maximiliano, Los Rotos y la Nación. Juan Rafael Allende entre la Guerra del Pacifico y la Guerra Civil de 1891, en Revista Mapocho, 55 (2004), p. 247, n. 181. Otros tristes ejemplos, especialmente de marinería abandonada en puertos europeos y americanos, en HARRIS BUCHER, Gilberto, Emigrantes, cit. esta nota, esp. pp. 140-151, con abundante casuística que podemos sintetizar con la frase "Suspirando por volver al terrón natal y arrepentidos por haber dejado Chile por una miserable pitanza".

5 Citado por Godor, Milton, La Aduana de hombres: discusión en torno a una propuesta de control popular, 1868-1872, en Revista Histórica 27, (Lima, 2003), p. 142.

${ }^{6}$ La industria, Iquique, 14 de noviembre de 1884, reproducido por Pinto Vallejos, Julio, Valdivia Ortiz de Zarate, Verónica y Artaza Barrios, Pablo, en Patria y clase en los albores de la identidad pampina, 1860-1890, en Historia, 36 (2003), p. 325.
} 
de los 30.000 chilenos enganchados, hacia 1872, había fallecido más del 50 por ciento $^{7}$, o sea, más que en la Guerra del Pacífico y la Guerra Civil de 1891. En fin, tantos excesos y tratos vejatorios motivarían al representante chileno acreditado en Arequipa a proponer, en 1871, la creación de "consulados ambulantes para optimizar la protección's. Aquello, en teoría, era una buena idea, puesto que, aunque se crearon muchos consulados y viceconsulados, especialmente en los países circunvecinos, -13 en Perú y Bolivia hasta 1875 y 11 allende Los Andes hasta caer el siglo- pero los ataché actuaban casi siempre ante hechos consumados e, inclusive, les rechazaban de plano las reclamaciones y, en ocasiones, hasta les cancelaban el respectivo exequator y, por lo mismo, la acción diplomática fue casi nula. Pero lo más importante es que nuestros gobiernos no los abandonaron a su suerte y, por lo mismo, la conexión entre el derrame de población y la apertura de legaciones es evidentísima, como hemos demostrado en otro lugar?

Y volviendo a Meiggs, señalemos que el conocido pago de Chile finalmente llegó. Apenas una subestación generadora de electricidad ubicada en el antiguo trazado Valparaíso-Santiago, en la gradiente que sube después de la estación de Llay-Llay hacia la capital, y un acotado barrio Meiggs recuerda a este norteamericano que falleció en el Perú en 1877. Pero anotemos algunas cuestiones sobre las cuales existe poca información, partiendo, extradición incluida, que en el Rimac fue desenmascarado por realizar lo que hoy llamamos 1 a v a d o d e di n e ro, es decir, fue un hábil corrupto que sirvió para satisfacer los apetitos de ministros y altos funcionarios del gobierno de Balta. ¿Cómo? Dineros provenientes de la casa Dreyfus, con la garantía del guano peruano, se utilizaron para construir una costosa red de ferrocarriles, costos que encubrían ganancias corruptas y que no fueron condenadas, conductas que no fueron conocidas por la opinión pública y tampoco por la justicia. Y se ha señalado que el $\mathrm{m}$ a g o de este intrincado proceso en la larga duración, junto con otras causas, condujo al descalabro financiero peruano ${ }^{10}$.

Como postdata, para todo, para nosotros después de espigar en muchos folios depositados en el Archivo Nacional y en algunos textos no patrioteros, no nos

${ }^{7}$ La República, Santiago, 13 de abril de 1872. Allí los editorialistas espetaban que morían "en medio de la miseria y del abandono más espantoso". En muchos documentos del periodo aparecen noticias de que por las tersianas y fiebres malignas esperaban la muerte tomando aguardiente, fumando y jugando al monte, noticia que se repite en diversos tramos ferrocarrileros proyectados y ejecutados en el Perú.

${ }^{8}$ El Cónsul de Chile en Arequipa al Ministro de Relaciones Exteriores, Arequipa, 19 de enero de 1871, en Memoria del Ministerio de Relaciones Exteriores (1871), p. 53. El mismo año un medio informativo chileno planteaba que "recibimos diariamente quejas sobre el abandono en que se les mantenía [a los carrilanos] en el Perú, sobre la ineficacia de la acción consular y sobre la nulidad de la iniciativa diplomática [...]" (El Mercurio, Valparaíso, 14 de febrero de 1871). Y particularizando más: "para todo ariqueño un chileno era un enemigo", KLAIVER, Jeffrey, Los cholos y los rotos. Actitudes raciales durante la Guerra del Pacífico, en Histórica, 2/1 (Lima, 1978), p. 26. Más todavía: en 1869 el diplomático Joaquín Godoy refería la a n i m o s i d a d contra los nuestros en Arequipa. Sobre esto, PINTO, Julio, et al, cit. (n. 6), pp. 292-293.

${ }^{9}$ Harris, Gilberto, Emigrantes, cit. (n. 4), I parte.

${ }^{10}$ Quiroz, Alfonso, Redes de corrupción en el Perú: Poder y venalidad desde el Virrey Amat a Montesinos, en Revista de Indias, 66 (Madrid, 2006), 236, p. 244. 
cabe duda alguna la identificación del roto con su patria o con el terrón natal ${ }^{11}$. Y no podría ser de otra manera si consideramos - lo señalamos no a manera de sarcasmo sino que tratando de entrar en su inescrutable psiquis, o sea, en el alma del roto marcada por lo infausto- que casi todos decían tener tres fincas en Chile o en el exterior: "el hospital, la cárcel y el cementerio" ${ }^{2}$. En cuanto a lo del camposanto aquello era casi imposible puesto que en tierras lejanas, especialmente en Perú y Bolivia, eran enterrados en cualquier lugar y con suerte en la lápida -si la había- aparecía un nombre o una fecha escrita con sangre. Crudamente, como no se verificaba la repatriación hasta los huesos del a roma patriota se desvanecían y todo por culpa de la pa tria in ter rumpida.

Pero por la falta de trabajo o mezquinos salarios - problema de larga duraciónresultaba casi imposible escapar a la tentación de la bandera de enganche color oro, amarillo reluciente, que en rigor atraía a muchos de los desheredados de todo y que flameó, antes y durante el ciclo salitrero, "en los campos sureños, callejuelas de pueblos rurales, en playas y villorrios, en las plazas de las ciudades centrales, en las estaciones ferroviarias, en los puertos del carbón, del trigo, del vino, de los minerales, en fin en cualquier parte"13 e incluso la prensa informaría, a propósito de las obras públicas peruanas, que se establecieron "agentes enganchadores en todos los pueblos para que nuestros obreros marchen como coolies de la China a trabajar en los ferrocarriles" ${ }^{14}$; más crudamente Zorobabel Rodríguez espetaba que más que una emigración era "una verdadera exportación, que no se van sino que se les arrea, que no se les persuade sino que se les engaña" ${ }^{15}$. En fin, Benjamín Vicuña Mackenna al hacer un balance sobre la sangría de población hacia el exterior indicó alguna vez lo que sigue: "emigración eterna del sur al centro y del centro al norte de Chile, lenta aunque constante de Chile a la República Argentina, rápida y transitoria a la Antigua California, violenta, gigantesca y desastrosa a los ferrocarriles del Perú" 16 .

Por último, el Canciller Ibáñez y el Intendente Echaurren fueron clarividentes en cuanto a las probables consecuencias de la emisión de nuestras peonadas, espetando el primero, en carta a los intendentes, que ese derrame eventualmente lesionaría las relaciones políticas con Perú; y el Intendente Echaurren advertía

11 Cuando se discutía en el Senado en 1871 una propuesta para levantar una "Aduana de Hombres” que prohibiera la salida de peones al Perú, Benjamín Vicuña Mackenna señalaba en una larguísima intervención legislativa una verdad incontestable: "He querido ser claro, y nada omitir de cuanto pudiera servir para fijar nuestros trabajadores al suelo en que nacieron, y al que aman de corazón; pero la miseria hace al hombre cosmopolita y donde halla su felicidad y su alimento allí está su patria”. Cámara de Senadores. Sesión Ordinaria del 31 de julio de 1871.

12 Don Cristóbal, 19. 4. 1890, en Salinas, Maximiliano, cit. (n. 4), p. 228.

13 Durán, Senén, El drama de los enganchados del salitre, en Tarapacá. Una aventura en el tiempo. Selecciones de Revista Camanchaca (Iquique, 1994), p. 12.

${ }^{14}$ El Mercurio, Valparaíso, 19 de mayo de 1871.

15 Rodríguez, Zorobabel, Emigración Chilena, en Miscelánea literaria, política y religiosa (Santiago, 1876), p. 212.

16 El Ferrocarril, Santiago, 2 de agosto de 1871. 
premonitoriamente un año antes, entre otros aspectos, la verificación de enojosos problemas diplomáticos ${ }^{17}$.

\section{Anexos}

RepresentaCión de CHILENOS AL ENCARGADO DE LA LEGACiÓN DE CHILE EN EL Perú acerca de eXcesos ocurridos en las obras del ferrocarril de ArequipaPuno. Arequipa, 14 de Diciembre de 1871

Archivo Nacional de Chile, Fondo Ministerio de Relaciones Exteriores, vol. 78.

Los que suscribimos, naturales y ciudadanos de la República de Chile y obreros de distintos ramos en la línea del ferrocarril que actualmente se construye de Arequipa a Puno en la República del Perú, con el debido respeto ante U. S. I. representamos: que en esta línea ocurren que pasan desapercibidos sin reparación ni justicia -muchas cosas-y que nada hacen los jefes de estos trabajos. El castigo cae inmediatamente sobre los chilenos en el -acto- que cometen alguna falta; pero cuando algunos jefes a un subalterno abusan de su autoridad y a quienes nos quejamos, y si reclamamos de la injusticia de alguno a los jefes superiores de la línea es en vano; se bastan con decir yo hablaré con él. Si ocurrimos a la autoridad local peruana, que es el Juez - de- primera instancia de la Provincia de Caillona -este- reside en Ichupanda [?] distante de la línea férrea-a- seis días de mal camino, que ocasiona retardo en los juicios y gastos $-\mathrm{y}-$ que solo el flete del caballo por cada vez importa veinte pesos. Así es que nos es imposible alcanzar justicia. Para los pobres trabajadores de cualquier nacionalidad que sean, no hay jueces, no hay leyes, ni garantías. No hay más que injusticias [ilegible] y violencia. Sería molestar la atención de U. V. S. expresar aquí todos nuestros sufrimientos; sin embargo -consignaremos-algunos hechos que patenticen nuestro cruel infortunio. Hemos venido a este país con el fin de trabajar en la obra del ferrocarril de Puno dejando la madre, la esposa, los hijos y en esta tierra extraña nos hallamos privados aun de los recursos necesarios para la vida, pues nos obligan a aceptar a la fuerza -trabajos- por la cantidad que quieren $-\mathrm{y}$ - de donde resulta que no nos alcanza para el alimento, ni para -reponer- la herramienta que se quiebra o se pierde. No se permite a ningún chileno el embarque o regreso a su país a pesar de hallarse cumplido el término de su enganche, y aunque trabaje voluntariamente sin tiempo determinado -y algunos que no han tenido ningún compromiso $y$ que se hallan trabajando en la ciudad de Arequipa de traficante u obreros- los han encontrado en la calle la partida de la línea -y- los han llevado a la fuerza y los han sometido a la misma obligación sin tener los infelices a quien reclamar. Cuando alguno, por no querer trabajar en días feriados, o por estar enfermo o comete alguna falta leve, los administradores de la faena -muy- luego echan mano

${ }_{17}$ Circular de Ibáñez a los Intendentes, Santiago, 22 de marzo de 1872, en Archivo Nacional. Fondo Intendencia de Valparaíso, vol. 263; Francisco Echaurren al Ministro del Interior, Valparaíso, 12 de abril y 24 de junio de 1871, en Archivo Nacional. Fondo Intendencia de Valparaíso, vol. 263. La información de Ibáñez a los intendentes también fue publicada en la prensa, pero con otro tenor. Véase La República, Santiago, 14 de abril de 1872. 
del revólver -y- si no lo tienen, por lo menos lo hacen poner a la barra o cepo de fierro sin comer, en la intemperie del sol y del frío, sin la menor compasión. Por no cansar la atención con varios hechos particulares nos ocuparemos solo del administrador D. Domingo Retamal que administra una faena; este como bebe mucho y a veces toma con los trabajadores, después riñe con ellos como lo hizo con D. N.; que lo hirió con el revólver. Otro día el mismo Retamal -al ver-que estaban en riñas el chileno Gil Marini con otro chileno herrero Delicio Delso, por esto Retamal le dio al primero con la culata del revólver que lo hirió en la cabeza. $\mathrm{Al}$ segundo le dio dos tiros $-\mathrm{y}$ - con uno le hizo volar el sombrero y con otro le -voló- un ojo. El nuevo cónsul de Chile en Arequipa se contentó con mandar los heridos al hospital. También habiendo ido donde el administrador D. Domingo Retamal, el chileno D. José Acencio Canales a pedirle hilo para coser una carpa, como es de costumbre, lo halló tomando y la contestación fue darle con la culata del revólver que lo hirió del ojo izquierdo, y trataba -de- hacerle puntos y otro lo contuvo, que si no lo mata seguramente. Entonces Canales no dio parte de este al primer jefe de la línea de Puno D. Juan Campbell porque a este señor no se le pueden quejar. Luego Canales le avisó al capitán de su campamento D. Guillermo. Wiman [¿̨?] este le reconvino a Retamal muy -ligeramente-. Después puso la queja al subdelegado D. Francisco Vicuña y este dijo yo hablaré con Retamal. Últimamente dio parte al señor Cónsul de Chile en Arequipa D. Baltazar Castillo y contestó gracias a Dios siempre tengo quejas [sic].

Por lo expuesto, conocerá U. S. I. que esta respetuosa solicitud no tiene otro objeto que poner en su conocimiento las barbaridades que cometen con los súbditos chilenos los jefes y administradores de estas faenas, y que para ellos no hay juzgamiento. A U. S. I. ocurrimos por la presente representación pidiendo su amparo y protección de nuestra vida e intereses: imploramos la separación de esta línea férrea de D. Domingo Retamal y su juzgamiento por juez competente; que hay pruebas de testigos que se nombrarán a su vez. También se dignará U. S. I. ponerse de acuerdo con el Supremo Gobierno del Perú para que el juez de -primera- instancia de Caylloma -que- reside en el pueblo de Yura de la provincia, durante esta obra férrea administre pronta e imparcial justicia. Que se nombre un superintendente de la línea y un abogado que esté en la línea para que oportunamente defienda a los trabajadores de la línea que firman bajo el peso de la arbitrariedad y de la esclavitud [ilegible]. U. S. I., protector de los súbditos de Chile en honor de la representación nacional y de la civilización y de la humanidad, esperamos ponga remedios a nuestra situación. Por tanto a U. S. I. rogamos acuda a nuestros[ilegible]- que conseguiremos de su magnanimidad. 
Representación de José Acencio Canales al Intendente de Valparaíso. AREQUiPA, 1872

Archivo Nacional de Chile, Fondo Ministerio de Relaciones Exteriores, vol. 70.

Muy Señor mío, con el debido respeto digo a V. S. que ya nos es insufrible a los chilenos las barbaries y abusos que cometen con nosotros los jefes y administradores de la línea férrea de Arequipa-para- Puno. Pondré en conocimiento de V. S. algunos datos ocurridos desde el catorce de diciembre de mil ochocientos setenta y uno desde que puse en conocimiento del Señor Ministro de Chile en Lima algunas ocurrencias, lo que puede confirmar desde esa fecha catorce de diciembre hasta estos momentos los lamentables y tristes acontecimientos que han contraído estos miserables y despatriados de Chile, y que no es menos de su crédito para Chile por el extranjero - de que-continuamente a su visita vean caer -y- descargar el más horrible epitafio que hace tronar en la debilidad de unos pocos miserables como los hijos de Chile hoy acá; y que no haya absolutamente un hombre que no respire una sola palabra por estos esclavos de D. Juan Campbell y del Señor-Enrique- Meiggs. Pero en fin principiaré por -el caso de- Bernardo Valdivia; este se encontraba enfermo en esa línea de Arequipa a Puno y el médico viendo que no le provocaba bien el temperamento le dio papel en el mes de noviembre de 1871 para que lo presentara a los jefes superiores para que le dieran su pasaje para Chile por enfermo. A más otro jefe también le dio papel a fin de que no le negaran su pasaporte. Dicho enfermo se vino -hacia- Arequipa -y- Mister Mayo, que le dicen -a ese- extranjero, le hizo tiras los papeles que este enfermo le presentó. Ya este pobre no puede moverse de -brazos-; la enfermedad [ilegible] y se recogió al Hospital de Arequipa; -así- ha pasado algún tiempo y lo han puesto de alta el 12 del presente mes. Así es de que este enfermo apenas anda por la calle con una pierna arrastrada, apoyado de un palo que le sirve de bastón. A cuántos trabajadores no les ha pasado y les pasa lo mismo; como -a-Aranda le sucedió en el campamento Aivampal. Estando enfermo le pidió a los jefes [ilegible] pasaje, -pero- no se lo dieron. De un momento a otro se postró -y- entró al hospital solo a morir. Cuántos de estos jefes y contratistas de esta línea férrea que les han dado -trabajos-a los trabajadores y después de concluido el trabajo no se los han pagado. De tal manera que no han tenido con qué pagará la mantención y el rigor de los justicias los ha hecho huir sin tener un pan que llevar para el camino costa de pruebas. El día 2 del presente mes el mayordomo del campamento de Cañague, D. Anrique N, alemán, le ha tirado un balazo al chileno Roberto Pastén el que le ha -herido- el brazo. Inquiriendo los motivos, -estos- han sido que estaban tomando y por medio del líquido se han disgustado -y- el extranjero alemán ha hecho uso del revólver; en la actualidad se encuentra el chileno en el hospital de Arequipa. El 11 del presente, en esta línea que hago mención, -en- donde llaman Totora alcanza un mayordomo llamado D. Tomás a un peruano (los que no conocen los apellidos de esos extranjeros por lo poco conocidos que son y griegos para pronunciarlos) -y- una vez que le alcanzo le preguntó si lleva plata; contesta el peruano que no. Entonces hace uso del revólver, el peruano huye y de atrás lo hiere de un brazo. Es lo que he podido imponerme ayer mismo de que ese 
peruano y-luego- le han sacado a -declarar-y que no ha vuelto al hospital, así es de que ignoro su paradero y que me parece que los justicias lo llevaban en debida forma por ser peruano. También los gobiernos de Arequipa nos han declarado la guerra a los chilenos; todo lo que por casualidad he llegado a saber pongo al alcance de su conocimiento V. S. En pocos días que aquí he llegado he visto cosas que se pueden comprobar. Augusto Ramírez, comerciante, -y- José del Carmen Ibacache, los dos chilenos, entraron estos -en-Arequipa con el fin de comprar lo que necesitaban; como a las ocho de la noche que se van a su alojamiento -ylos toma presos la policía. [José del Carmen] Ibacache por decirles qué delito habían cometido para que los tomasen presos, sin más que esto un policial le dio con la culata del rifle que le rompió la cara -y- que se bañó en sangre. Otros dos chilenos más, en la misma noche, los tomaron presos -y- que recién llegaban del puerto de Ilo: Domingo Riberos y Prudencio Riberos; sus delitos de todos estos -fueron- porque no traían papel de sus patrones de donde trabajaban. Al otro día los sacaron a trabajar a las obras públicas. -Yo- le hice presente al Subprefecto, -pero- no hubo lugar a reclamo. Al segundo día como a las nueve pusieron en libertad a Agustín Ramírez y a José del Carmen Ibacache, quitándoles cinco pesos a cada uno y sin darles ni un centavo diario a ninguno de ellos. Al tercer día a Domingo Riberos y a Prudencio Riberos los vi trabajando y me dijeron que no les habían dado absolutamente nada para el -alimento-; mas no sé qué fin tendrían. Además se me ha dicho que a un chileno lo han herido en la estación de policía; otro más ha sido herido por la policía en la Plaza de Armas. A este -último- lo tenían trabajando. Si un chileno ocupa a un juez en esta ciudad no le hace justicia y para mayor desgracia que aquí no tenemos Cónsul a quien reclamar justicia. El que tenemos [¿ंen?] bien pueden estar matando a los chilenos en la misma puerta de su casa -y- seguro que él no se mueve. Que tal Cónsul es, que ni los niños de este pueblo le tienen respeto. Aquí se deja ver el respeto que le tienen. Le pide papel un chileno por dos o tres días para que el pueblo no le incomode -y- por darle su firma le pide cinco reales. Lo encuentran los Comisarios de la línea por la calle, les pasa el chileno la firma del Cónsul que anda trayendo para su resguardo -y- se la hacen pedazos y lo mandan a la estación y lo embarcan en la máquina para la línea. V. S. [ilegible] que acompaño es la que hemos mandado al Señor Ureta para que por mano de este señor la entregue al Encargado de la Legación de Chile en Lima. El Señor Ureta contestó que tan pronto recibió la entregó; así de que hasta ahora no hemos tenido contestación del señor Ministro. También le suplico a V. S. [ilegible] tomar preso a Claudio Arismendi que ha traído dos enganches de trabajadores, engañándolos -al decirles- que aquí ganan cinco pesos por día -pero- los que no les alcanzan para el alimento. Él es un hombre de cuerpo bajo, rubio, canoso, de patilla; me han dicho que en este vapor [?] llega aquí a Valparaíso. V. S. no le hago más referencias por falta de tiempo ya que el correo se me va. En caso - de- existir pruebas para su juzgamiento de Claudio Arismendi oficiaré al abogado D. Manuel Velarde en Arequipa que pronto las tendrá acá. Dios guarde a V. S. José Acencio Canales. 
